\title{
Effective Method for Preparing Low-Oxygen Titanium Ingot by Combined Powder Deoxidation and Vacuum Arc Melting Processes
}

\author{
Jung-Min $\mathrm{Oh}^{\mathbf{1}}$, Jaeyeol Yang ${ }^{2}$, Jaesik $\mathbf{Y o o n}^{2}$, and Jae-Won Lim ${ }^{1, *}$ \\ ${ }^{I}$ Division of Advanced Materials Engineering and Research Center for Advanced Materials Development, \\ College of Engineering, Jeonbuk National University, Jeonju 54896, Republic of Korea \\ ${ }^{2}$ Division of Earth and Environmental Science, Korea Basic Science Institute, Cheongju 28119, Republic of Korea
}

\begin{abstract}
In this study, an effective method is demonstrated for fabricating titanium sputtering targets, which are used to fabricate thin films in the semiconductor industry. The method is an alternative to the existing electron beam melting (EBM) process under high vacuum. Titanium sputtering targets used in the production of semiconductors must have very low concentrations of gaseous impurities, especially oxygen, as well as metal impurities. Currently, the oxygen concentration in titanium sputtering targets used for industrial purposes is less than $400 \mathrm{ppm}$. To develop an effective alternative method, powder metallurgy and melting processes were performed to prepare a low-oxygen titanium ingot with less than 400 ppm oxygen. First, titanium powder was deoxidized using calcium vapor, and then the powder was subjected to vacuum arc melting (VAM). The oxygen in the titanium powder was reduced with calcium vapor from an initial concentration of $2200 \mathrm{ppm}$ to $800 \mathrm{ppm}$, and the resulting powder was melted using VAM, resulting in titanium ingots with low oxygen content, $400 \mathrm{ppm}$ or less. It was also confirmed that all lattice constants, i.e., $d, a, c$, and $c / a$, decreased as oxygen concentration decreased in both the titanium powder and the ingots.
\end{abstract}

(Received December 28, 2020; Accepted February 1, 2021)

Keywords: titanium, sputtering target, oxygen, deoxidation, powder, melting

\section{Introduction}

High-purity titanium is primarily used in the high-tech electronics industry as a raw material for sputtering targets, to form thin films on semiconductors [1,2]. Honeywell (USA) and Toho (Japan), the world's largest manufacturers of Ti for this use, currently manufacture titanium sputtering targets with a purity of over $99.995 \%$ (impurity concentration: $<50$ ppm). (Purity here refers to the sum of metallic impurities excluding titanium itself.) Other than metallic impurities, the element that requires the highest control is oxygen. Oxygen in titanium not only has a considerable effect on both the electrical and mechanical properties of titanium sputtering targets [3], once it has dissolved, it forms a strong oxide film that is very difficult to remove [4,5]. Manufacturers use a small quantity of the cleanest titanium from the center of a

- 오정민: 연구교수, 양재열·윤재식: 연구원, 임재원: 교수

*Corresponding Author: Jae-Won Lim

[Tel: +82-63-270-2307, E-mail: jwlim@jbnu.ac.kr]

Copyright (c) The Korean Institute of Metals and Materials sponge titanium, which is prepared by blocking gas contaminants during the manufacturing phase. The selected titanium is then used to fabricate ingots via electron beam melting (EBM) [3]. Honeywell and Toho currently control the oxygen concentration of high-purity titanium sputtering targets to below $400 \mathrm{ppm}$; that is, the oxygen concentration in titanium sputtering targets must not exceed $400 \mathrm{ppm}$. However, titanium has high oxygen solubility [4,5], and removing oxygen from bulk titanium is also very difficult, since the surface area that can react with the deoxidation agent is very small, thus limiting the deoxidation reaction. Research on the deoxidization of bulk titanium has primarily been conducted using relatively small specimens, such as wires [6,7]. Moreover, numerous studies have reported that titanium powder, which has a response surface area larger than that of bulk titanium, can be deoxidized by reacting it with reactive materials. In addition, various methods have been proposed which prepare satisfactory titanium ingots by melting deoxidized titanium powder. However, since the residual oxygen concentration in those titanium ingots was 
high, they could not be used as sputtering targets. It has been shown that deoxidation-melting is also very useful for preparing low-oxygen titanium ingots [8]. In this study, titanium powder was deoxidized using calcium vapor, and this powder was subjected to vacuum arc melting (VAM) to finally obtain low-oxygen titanium ingots for use as the raw material for titanium sputtering targets.

\section{Experimental Procedures}

Titanium powder (purity: 99.9\%) and calcium (purity: 99.5\%) were purchased from High Purity Chemicals (Japan) and Junsei (Japan), respectively. The deoxidation experiment involved a specially prepared deoxidation pot that did not permit contact between the calcium and titanium powders. A schematic diagram of the deoxidation experiment conducted in this study is shown in Fig. 1. The deoxidation pot containing the titanium powder and calcium was inserted into a vacuum furnace, and the furnace was evacuated to a vacuum of $6.7 \times 10^{-3} \mathrm{~Pa}$. The furnace temperature was then raised to 1173-1273 K and maintained for $2 \mathrm{~h}$. The resulting deoxidized titanium powder was then compressed into a tablet $(30 \mathrm{~g}$, $\varnothing 25 \mathrm{~mm}$ ) for VAM. The titanium compact was placed into a water-cooled copper mold in a melting furnace at a base vacuum pressure of $1.3 \times 10^{-3} \mathrm{~Pa}$ before introducing $\mathrm{Ar}$ gas



Fig. 1. Schematic diagram of deoxidation of titanium powder by using calcium vapor. (purity: 99.9999\%). The titanium compaction was melted at $300 \mathrm{~A}$ and $10 \mathrm{~V}$ in an Ar atmosphere 4 times. Oxygen concentration in the titanium powder and the ingots was then measured using an oxygen gas analyzer (LECO, TCH-600). The average error range for the oxygen gas analyzer was $\pm 50 \mathrm{ppm}$. X-ray diffraction analysis (Shimadzu co., XRD6100) was performed to identify the lattice parameters and phase changes in the titanium powder and ingot.

\section{Results and Discussion}

In this study, low-oxygen ingots were prepared using VAM, which is among the typical methods used for melting titanium. VAM is currently the most commonly used process in industry.

We began by examining the change in the oxygen concentration of the bulk titanium during re-melting by VAM. Figure 2(a) shows the behavior of oxygen concentration while melting the bulk titanium at varying oxygen concentrations. The oxygen concentration of the initial bulk titanium was 400-3500 ppm, and sputtering targets and raw materials of industrial-grade G1-G4 were used. The oxygen in ingots prepared using VAM declined at the low reduction rate of $0.1 \%-1.8 \%$. In actuality, since the standard deviation of a gas analyzer is $\pm 50 \mathrm{ppm}$, there was little reduction in oxygen. Oxygen within metal can generally be removed through sub-oxide formation during melting [9]; however, reducing the oxygen in titanium is difficult because its affinity with oxygen is high, and it forms $\mathrm{TiO}_{2}$, a very powerful and stable oxide film [10]. Therefore, in this study, reducing oxygen by melting bulk titanium appeared unlikely.

Next, the change in oxygen concentration was investigated when the ingot was prepared using titanium powder as the raw material, rather than its bulk form. The oxygen concentration of the initial titanium powder ranged from 1750 to $4460 \mathrm{ppm}$. The reduction rate of oxygen concentration by VAM melting was high, extending from a minimum of $12.2 \%$ to a maximum of $24.5 \%$. The variation in oxygen concentration during the melting of the titanium powder is shown in Figure 2(b).

The oxygen concentration in titanium powder is known to mostly be in the form of $\mathrm{TiO}_{2}$ and forms with a larger specific surface area (SSA) than in an ingot [11]. It is likely 

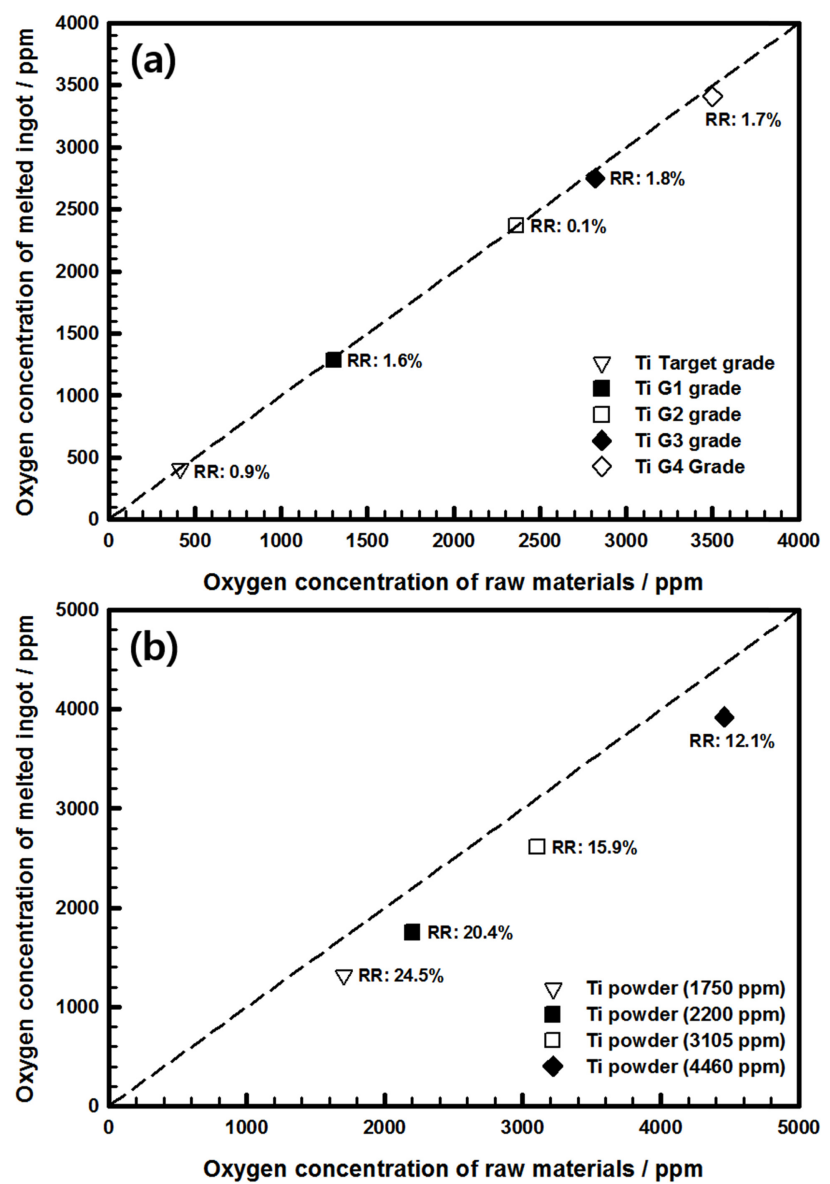

Fig. 2. Variation in oxygen concentration of melted ingots prepared from (a) bulk titanium and (b) after subjecting powder to VAM.

that the oxygen concentration is further reduced as these $\mathrm{TiO}_{2}$ layers change from powder to a bulk form, ingots, since the SSA decreases significantly. The actual oxygen concentration in a titanium ingot and in powder form is determined by the following equation [12]:

$$
\begin{aligned}
\mathrm{O}_{\text {total }} & =\mathrm{O}_{\text {inside }}+\mathrm{O}_{\text {surface }}=\mathrm{O}_{\text {inside }}+a \times t \times \mathrm{P}_{\mathrm{TiO} 2} \times \mathrm{O}_{\mathrm{TiO} 2}= \\
\mathrm{O}_{\text {inside }} & +1.69 \times 10^{8} t a
\end{aligned}
$$

where $a$ is the SSA of the titanium powder, $t$ is the thickness of the $\mathrm{TiO}_{2}$ layer, $\mathrm{P}_{\mathrm{TiO} 2}$ is the density of $\mathrm{TiO}_{2}$ layer, and $\mathrm{O}_{\mathrm{TiO} 2}$ is the weight percent of $\mathrm{TiO}_{2}$. Since $\mathrm{O}_{\text {inside, }}, t, \mathrm{P}_{\mathrm{TiO} 2}$, and $\mathrm{O}_{\mathrm{TiO} 2}$ don't change during production, it can be considered that the factor that most greatly impacts oxygen concentration is the SSA. As a result, the effect of oxygen concentration reduction depends on the SSA of titanium. In a prior study, we confirmed the above equation by comparing the oxygen concentration reduction effect observed by varying the amount of titanium powder [11]. In that study, the values of oxygen concentration in the titanium powder specimens with particle sizes averaging $60 \mu \mathrm{m}, 125 \mu \mathrm{m}$, and $250 \mu \mathrm{m}$ were $2840 \mathrm{ppm}, 2050 \mathrm{ppm}$, and $1700 \mathrm{ppm}$, respectively. And, the values of the SSA were $3.5 \mathrm{~m}^{2} / \mathrm{g}, 2.0 \mathrm{~m}^{2} / \mathrm{g}$, and $0.5 \mathrm{~m}^{2} / \mathrm{g}$, respectively. From these results, it can be seen that the oxygen concentration depends on the SSA, assuming that there is no change in the inside oxygen concentration due to pulverization of the titanium powder, and that the thickness of $\mathrm{TiO}_{2}$ is constant.

Therefore, in this study, the deoxidation effect was maximized by using the calcium vapor (DCV) method [11], which we developed using titanium powder as a raw material. A low-oxygen ingot was prepared through VAM. Variation in the reduction rate of the oxygen concentration of the ingots prepared by VAM from deoxidized titanium powder are shown in Figure 3. The oxygen concentration of the initial titanium powder was determined to be $2200 \mathrm{ppm}$. After deoxidation at $1173 \mathrm{~K}$ and $1273 \mathrm{~K}$ by DCV, the oxygen was reduced to $890 \mathrm{ppm}$ and $800 \mathrm{ppm}$, respectively, a reduction rate of over $60 \%$. In comparison, the oxygen reduction rate did not exceed $40 \%$ when the same titanium powder was deoxidized at $1073 \mathrm{~K}$ using a conventional method [8].

When the titanium powder was deoxidized by DCV, 1273 $\mathrm{K}$ was found to be the optimum temperature. Several factors explain the extent of the titanium powder deoxidation at temperatures both below and above the melting point of



Fig. 3. Oxygen concentrations and removal rates for the powder, deoxidized powder, and ingot. 
calcium. In the first place, self-diffusion of the solid-solution elements in titanium begins at $943 \mathrm{~K}$, indicating that the selfdiffusion of oxygen leads to higher deoxidation at temperatures above this value. In addition, the equilibrium vapor pressure of calcium increases with increasing temperature, causing it to react actively with titanium at high temperatures. According to our calculations, the calcium vapor pressure at $973 \mathrm{~K}, 1073 \mathrm{~K}, 1173 \mathrm{~K}$, and $1273 \mathrm{~K}$ was $14.4,103,500$, and $1750 \mathrm{~Pa}$, respectively. Pure titanium exists as $\alpha$-titanium at room temperature and transforms to $\beta$ titanium at $1155 \mathrm{~K}$. During this transformation, its crystal structure transfers from hexagonal close packed (HCP) to body centered cubic (BCC), and this allows more space for the oxygen to move.

When the ingot specimens were prepared through VAM using this initially deoxidized titanium powder, it was found that their oxygen concentration was reduced by approximately 400-600 ppm compared to their initial concentration. When the initial 2200 ppm powder was deoxidized at $1273 \mathrm{~K}$, the oxygen concentration was reduced to $800 \mathrm{ppm}$, while in the ingots it was further reduced to $385 \mathrm{ppm}$ by melting the deoxidized titanium powder. As a result, the reduction rate of oxygen concentration during the transformation from titanium powder to ingots was above $82.5 \%$.

Similar results have been reported by other researchers; the Kim group have reported that when titanium powder with an oxygen concentration above 2000 ppm was melted by EBM, the oxygen concentration reduction was approximately 600 ppm [13]. It is known that the oxygen reduction of titanium powder from the molten metal pool is proceeded by the reduction of the combined oxygen by the vaporization of metal oxides, predominantly a sub-oxide of titanium, and volatile or unstable (over melting temperature) impurity oxides with higher affinity to the oxygen [14].

In addition, the reduced oxygen affects the lattice structure of these deoxidized powders and ingots. Figure 4(a) shows the $\mathrm{XRD}$ results of the raw powder, deoxidized powder, and ingot. All of the samples showed diffraction peaks corresponding to $\alpha$ titanium. The XRD results showed that all the diffraction peaks of the deoxidized titanium powder and ingot shifted to higher angles, and the interplanar spacing $\left(d_{1011}\right)$ values decreased slightly compared to the raw titanium powder. The decrease in interplanar spacing $\left(d_{1011}\right)$ within the lattice of the deoxidized titanium powder and ingot is considered to be due to the reduced oxygen concentration, as the solid solution oxygen, an interstitial atom, affects the lattice parameters.
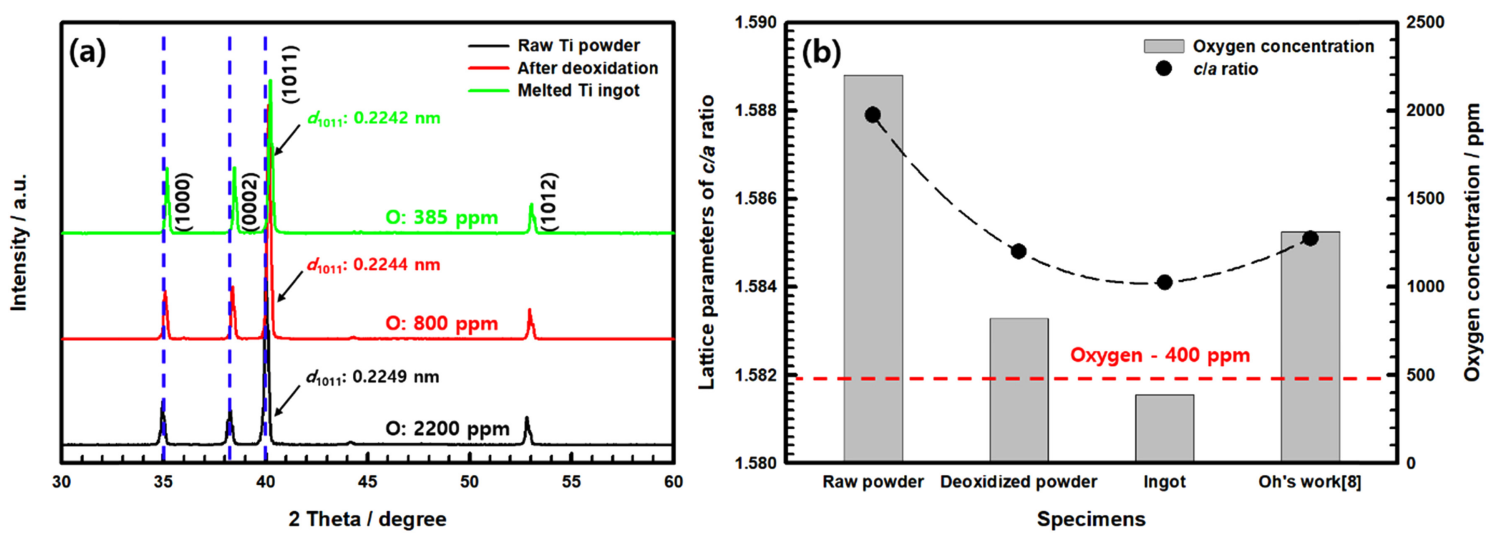

Fig. 4. (a) XRD patterns and (b) variation in lattice parameters and oxygen concentration of raw powder, deoxidized powder, and ingot.

Table 1. Lattice parameters $d, a, c$, and $c / a$ ratios for raw powder, deoxidized powder and ingot.

\begin{tabular}{cccccc}
\hline Specimens & \multirow{2}{*}{ Oxygen $(\mathrm{ppm})$} & \multicolumn{4}{c}{ Lattice parameters } \\
\cline { 3 - 6 } & & $d_{1011}(\mathrm{~nm})$ & $a(\mathrm{~nm})$ & $c(\mathrm{~nm})$ & $c / a$ \\
\hline Raw powder & 2200 & 0.2249 & 0.2946 & 0.4678 & 1.5879 \\
Deoxidized powder at 1273K & 800 & 0.2244 & 0.2946 & 0.4669 & 1.5848 \\
Ingot & 385 & 0.2242 & 0.2946 & 0.4667 & 1.5841 \\
\hline
\end{tabular}




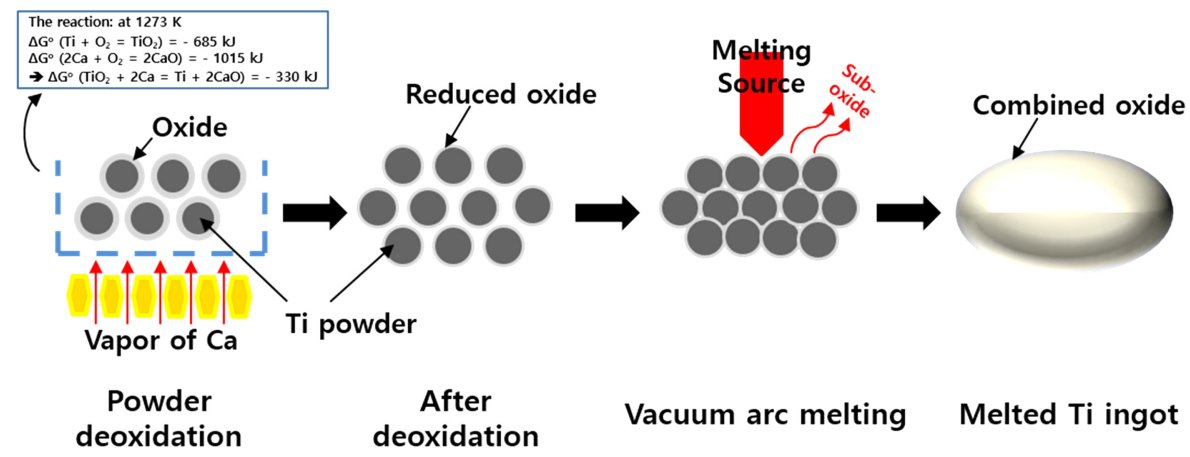

Fig. 5. Schematic showing mechanism of morphological variation and increase in volume of titanium powder after VAM.

The lattice parameters of the ingots prepared by VAM, based on the materials used, and powder deoxidized at $1273 \mathrm{~K}$ were measured and are shown in Table 1. As shown, all of the $c$ axis and $c / a$ axis ratio lattice parameters decreased with the decrease in oxygen concentration. In particular, the results show that the $c / a$ axis ratio in the HCP structure decreased linearly with decreasing oxygen concentration. It can be seen that oxygen atoms are more likely to escape from the $c$-axis, which is longer than the $a$-axis, as shown in Figure 4(b).

Figure 5 illustrates the behavior of oxygen when titanium powder is initially deoxidized and subsequently melted to form an ingot. First, the oxygen in the titanium powder is actively diffused to the surface as the deoxidation temperature increases. This oxygen moves to the surface of the titanium where it produces titanium oxide, is then decomposed by calcium vapor, and finally is reduced to calcium oxide. In addition, there is a decrease in the amount of oxygen inside the titanium powder. There are two main mechanisms for the elimination of oxygen from titanium using calcium: (1) elimination of the $\mathrm{TiO}_{2}$ layer on the titanium surface and (2) elimination of the oxygen inside the titanium [11]. The mechanisms can be explained by the following reactions:

(1) $\mathrm{TiO}_{2}$ (on the surface area) $+2 \mathrm{Ca}=\mathrm{Ti}+2 \mathrm{CaO}$

(2) $\mathrm{O}$ (solid-solution in the titanium) $+\mathrm{Ca}=\mathrm{CaO}$

Oxygen (solid-solution in the titanium) was shifted to oxygen diffusion region.

$\mathrm{O}$ (in the oxygen diffusion region) $+\mathrm{Ti}=\mathrm{TiOx}$

TiOx (on the surface area) $+x \mathrm{Ca}=\mathrm{Ti}+\mathrm{xCaO}$

Later, low-oxygen titanium ingots were prepared by VAM. A single bulk shape was formed as the oxide film on the high surface area titanium powder was removed. The behavior of the oxide film and its interior oxygen concentration during the deoxidation process were observed using TEM and SIMS depth profiles [15]. Low-oxygen titanium ingots were prepared from titanium powder with a large response surface area, for use as sputtering targets, after which the powder was subjected to VAM to form ingots.

\section{Conclusions}

To prepare a low-oxygen titanium ingot for use as a raw material for sputtering targets, titanium powder was first deoxidized by DCV and a low-oxygen ingot was prepared using VAM. With the bulk titanium, there was hardly any reduction in oxygen concentration in ingots prepared using VAM. However, when titanium powder was used, the oxygen concentration was reduced by DCV to $800 \mathrm{ppm}$ from an initial $2200 \mathrm{ppm}$. When the powder was subsequently melted using VAM, the oxygen concentration was further reduced to 385 ppm. In our estimation, this technique thus provides a suitable method for fabricating low-oxygen titanium ingots as a raw material for the manufacture of titanium sputtering targets.

\section{Acknowledgements}

This work was supported by the Korea Institute of Energy Technology Evaluation and Planning (KETEP) and the Ministry of Trade, Industry \& Energy (MOTIE) of the Republic of Korea (No. 20185210100030). And, this research was supported by Basic Science Research Program 
through the National Research Foundation of Korea(NRF) funded by the Ministry of Education (2020R1I1A1A01063 013). This paper was proofread by the Writing Center at Jeonbuk National University in December 2020.

\section{REFERENCES}

1. Y. Fan, C. Zhang, X. Liu, Y. Lin, G. Gao, Y. Yin, and X. Li, J. Alloys Compd. 786, 607 (2019).

2. T. Ponken and T. Burinprakhon, Thin Solid Films. 681, 6 (2019).

3. G. Lutjering and J. Williams, Titanium, p.78, Springer, Berlin (2007).

4. R. O. Suzuki, K. Teranuma, and K. Ono, Metall. Mater. Trans. B. 34, 287 (2003).

5. J. Chae, J.-M. Oh, S. Yoo, and J.-W. Lim, Korean J. Met. Mater. 57, 569 (2019).

6. M. H. Song, S. M. Han, D. J. Min, G. S. Choi, and J. H. Park, Scr. Mater. 59, 623 (2008).
7. T. H. Okabe, T. Oishi, and K. Ono, Metall. Trans. B. 23, 583 (1992).

8. J. M. Oh, B. K. Lee, C. Y. Suh, S. W. Cho, and J. W. Lim, Mater. Trans. 53, 1075 (2012).

9. C. K. Gupta, D. K. Bose, and N. Kishnamurthy, J. Less Common Met. 139, 189 (1988).

10. Y. Zhang, J. Li, S. Che, and Y. Tian, Met. Mater. Int. 26, 783 (2020).

11. J. M. Oh, C. I. Hong, and J. W. Lim, Adv. Powder Technol. 30, 1 (2019).

12. P. Sun, Z. Z. Fang, Y. Xia, Y. Zhang, and C. Zhou, Powder Technol. 301, 331 (2016).

13. H. K. Park, Y. K. Ahn, B. S. Lee, K. H. Jung, and H. G. Kim, Mater. Lett. 187, 98 (2017).

14. K. Vutova, V. Vassileva, E. Koleva, E. Georgieva, G. Mladenov, D. Mollov, and M. Kardjiev, J. Mater. Process. Technol. 210, 1089 (2010).

15. J. M. Oh, H. Kwon, W. Kim, and J. W. Lim, Thin Solid Films. 551, 98 (2014). 